\title{
What about vaginal extraction of the kidney? results of an online survey
}

João Ferreira Cabral 1, Isaac Campos Braga 1, 2, Frederico Branco ${ }^{1}$, Vitor Cavadas ${ }^{1}$, Avelino Fraga Ferreira ${ }^{1,3}$, Miguel Silva Ramos ${ }^{1}$

${ }^{1}$ Departamento de Urologia, Hospital de Santo António - C.H.P, Porto, Portugal; ${ }^{2}$ Instituto de Investigação em Ciências da Vida e da Saúde - I.C.V.S, Universidade do Minho; ICVS/3B's - PT Laboratório Associado ao Governo, Braga, Portugal; ${ }^{3}$ Instituto de Ciências Biomédicas Abel Salazar - I.C.B.A.S - Universidade do Porto, Porto, Portugal

\section{ABSTRACT}

Purpose: We aimed to characterize surgeons opinion about the vaginal extraction of the kidney after transperitoneal laparoscopic nephrectomy.

Matherial and Methods: A 9-item questionnaire was published online (Survey Monkey TM) and publicized via email to a multidisciplinary pool of surgeons in Portugal.

Data was collected and statistical analysis was performed using IBM SPSS Statistics, Version 21.0.

Results: Three hundred and fifty nine inquiries were sent, 154 surgeons completed the questionnaires (response rate of 43.0\%). Fifty five point eight percent of the participants would choose the transvaginal approach for themselves or for a close relative. The most stated arguments were a better cosmesis (29.0\%) expectancy of lower post operative pain (26.0\%) and lower rate of incisional hernias (23.0\%). Defenders of the transabdominal procedure justified with an expectancy of lower complication rate (39\%), namely impairment of sexual function and fertility (22\%). The female gender and the familiarity with transvaginal surgery were the stronger predictors of the option for this approach $(70.6 \%$ vs $48.5 \%$; $\mathrm{p}=0,016$ and $85.3 \%$ vs $46.6 \%$; $\mathrm{p}<0.001$ respectively).

Conclusions: Contrasting with similar surveys published on transvaginal NOTES, the vaginal specimen extraction after conventional laparoscopic nephrectomy was fairly accepted by the inquired surgeons.

\section{ARTICLE INFO}

\section{Key words:}

Endoscopy; Kidney; Vagina

Int Braz J Urol. 2016; 42: 78-82

Submitted for publication:

March 25, 2015

Accepted after revision:

July 20, 2015

\section{INTRODUCTION}

Natural orifice transluminal endoscopic surgery (NOTES) is to be implemented for almost a decade. However, because of the lack of appropriate armamentarium and unproven safety, the technique presented in 2006 as "the new paradigm of surgery" (1), has hardly surpassed the initial barriers.

Contrarily, the natural orifices specimen extraction (NOSE) has proven to be feasible and safe (2-6) allowing the retrieval of surgical specimens after standard or mini laparoscopy.
Morcellation is another alternative for specimen retrieval without the need of wound enlargement; however, risks of intra-abdominal lesions, tumor seeding and impaired pathologic examination still elicit concerns in surgical community (7).

In the urological field, the first NOSE procedure was reported by Breda in 1993 (8), who first performed a transvaginal retrieval of a kidney specimen. In 2002 Gill reported a series of 10 laparoscopic radical nephrectomies followed by vaginal extraction (9) and in 2011 Alcaraz tested the safety of the procedure to the limit, reporting a series of 20 living donor laparoscopic nephrectomies with vaginal delivery (6). 
However, the technique did not have a great spread, remaining confined to some high specialized centers (10).

We decided to conduct a survey directed to surgeons to better understand their opinion about the vaginal extraction of nephrectomy specimens.

\section{MATERIALS AND METHODS}

We designed a survey in Portuguese language, consisting of a 9-item questionnaire (appendix) to evaluate five main items:

Personal and professional data, practice of laparoscopy, practice of transvaginal surgery, personal choice for kidney retrieval and justification of the option.

The inquiry was published online on a proper website (Survey Monkey ${ }^{\mathrm{TM}}$, Palo Alto, USA) and publicized via email to a multidisciplinary pool of surgeons, encompassing general surgeons, urologists and gynecologists, from three major surgical societies in Portugal.

No email reminders were sent in order to prevent re-answering.

Data was collected and statistical analysis was performed using IBM SPSS Statistics, Version 21.0 (IBM, New York, USA). Continuous data are expressed as mean and standard deviation. Chi square test was used for comparison of categorical variables with a significance level of 0.05 .

\section{RESULTS}

Three hundred and fifty nine inquiries were sent and 154 surgeons completed the questionnaires (response rate of 43.0\%) (Table-1).

Fifty five point eight percent of the respondents would choose the transvaginal approach for kidney retrieval for themselves or for a close relative.

The most stated arguments were a better cosmesis (29.0\%) and expectancy of lower post operative pain $(26.0 \%)$. Defenders of the transabdominal procedure justified with an expectancy of lower complication rate (39\%), namely impairment of sexual function and fertility (22\%) (Figures 1 and 2).
Table 1 - Demographic and Professional Data.

\begin{tabular}{lc}
\hline Variable & $\mathrm{N}=154$ \\
\hline \multicolumn{1}{c}{ Age (Mean \pm SD) } & $39.52( \pm 10.7)$ \\
Gender & $66.8 \%$ \\
Differentiation & \\
Specialist & $59,7 \%$ \\
Specialty & \\
Urologists & $44.2 \%$ \\
General Surgeons & $31.2 \%$ \\
Gynecologists & $24.7 \%$ \\
Practice of Laparoscopy & \\
No & $16.2 \%$ \\
$<20$ annual procedures & $35.7 \%$ \\
$\geq 20$ annual procedures & $48.1 \%$ \\
Practice of Transvaginal Surgery & $22.1 \%$ \\
\hline
\end{tabular}

Figure 1 - Surgeons option considering the area of specialization.

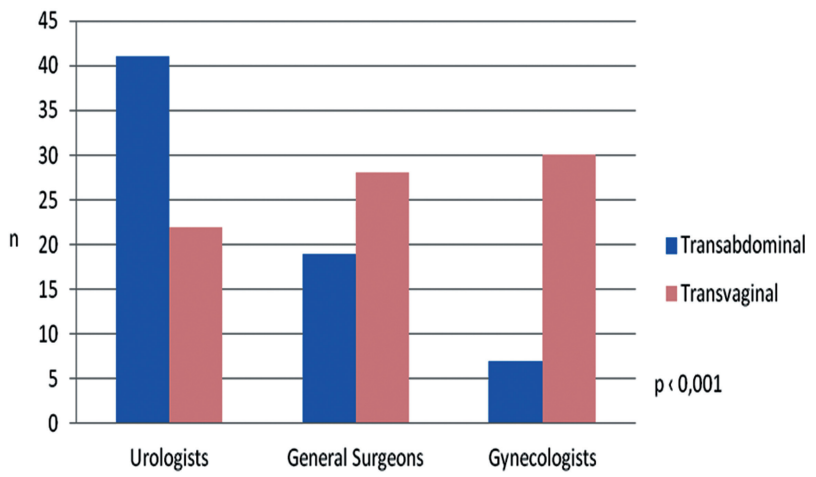

Female surgeons showed preference for the transvaginal access (70.6\% vs $48.5 \% ; p=0.016)$.

Gynecologists and General surgeons were most likely to choose the transvaginal approach (81.5\% and 60.4\% respectively), while among the urologists only $38.2 \%$ would opt for this access $(\mathrm{p}<0.001)$ (Figure-3). 
Figure 2 - Mentioned arguments favoring the transabdominal approach.

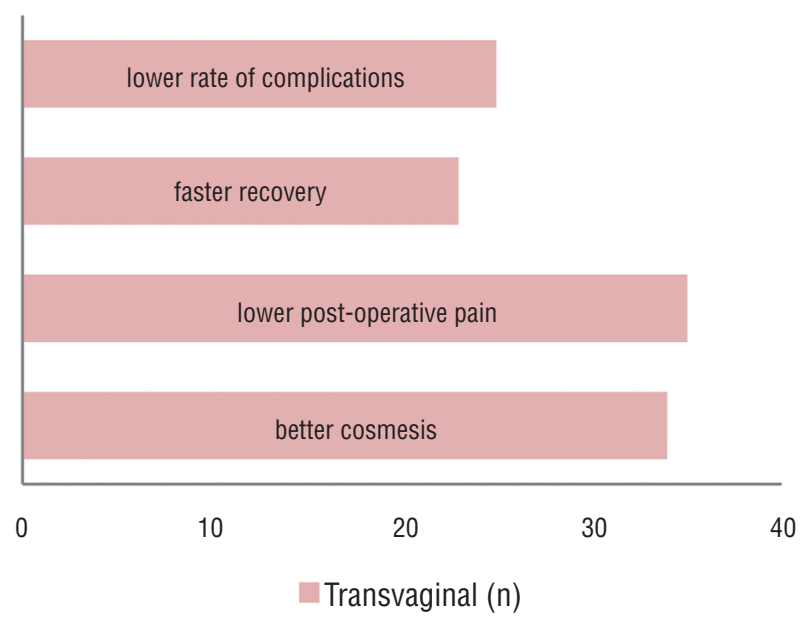

There was no difference in the option between residents and specialists (53.2\% versus $57.6 \%$ respectively; $\mathrm{p}=0.71$ ).

There was no statistical difference related with the reported number of laparoscopic procedures performed annually and the preference for the transvaginal approach.

The familiarity with transvaginal surgery was the strongest predictor of the option for this approach (85.3\% vs. $46.6 \% ; \mathrm{p}<0.001)$.

\section{DISCUSSION}

In our survey, the majority of the inquired surgeons privileged the transvaginal extraction of nephrectomy specimens over its transabdominal counterpart.

Gynecologists were the most enthusiasts, which is coherent with the fact that gynecologists perform transvaginal surgery for decades. In fact, $90 \%$ of the surgeons that stated practice of transvaginal surgery were gynecologists.

Urologists were the least like to choose the transvaginal approach. A possible explanation may be related with the number of patients amenable for vaginal extraction, which, in the majority of centers is probably too small to sensitize surgeons and to justify specific training. Excluding most of the tumors, because of specimen size, and living donors, which are only performed in specific centers, the majority of urologists can only count on excluded kidneys to get experience on vaginal extraction.

Overall, the expectation of lower post operative pain and better cosmesis were the most mentioned arguments by enthusiasts of the transvaginal retrieval, which is in general agreement with results of similar surveys on NOTES and LESS (11).

Figure 3 - Mentioned arguments favoring the transabdominal approach.

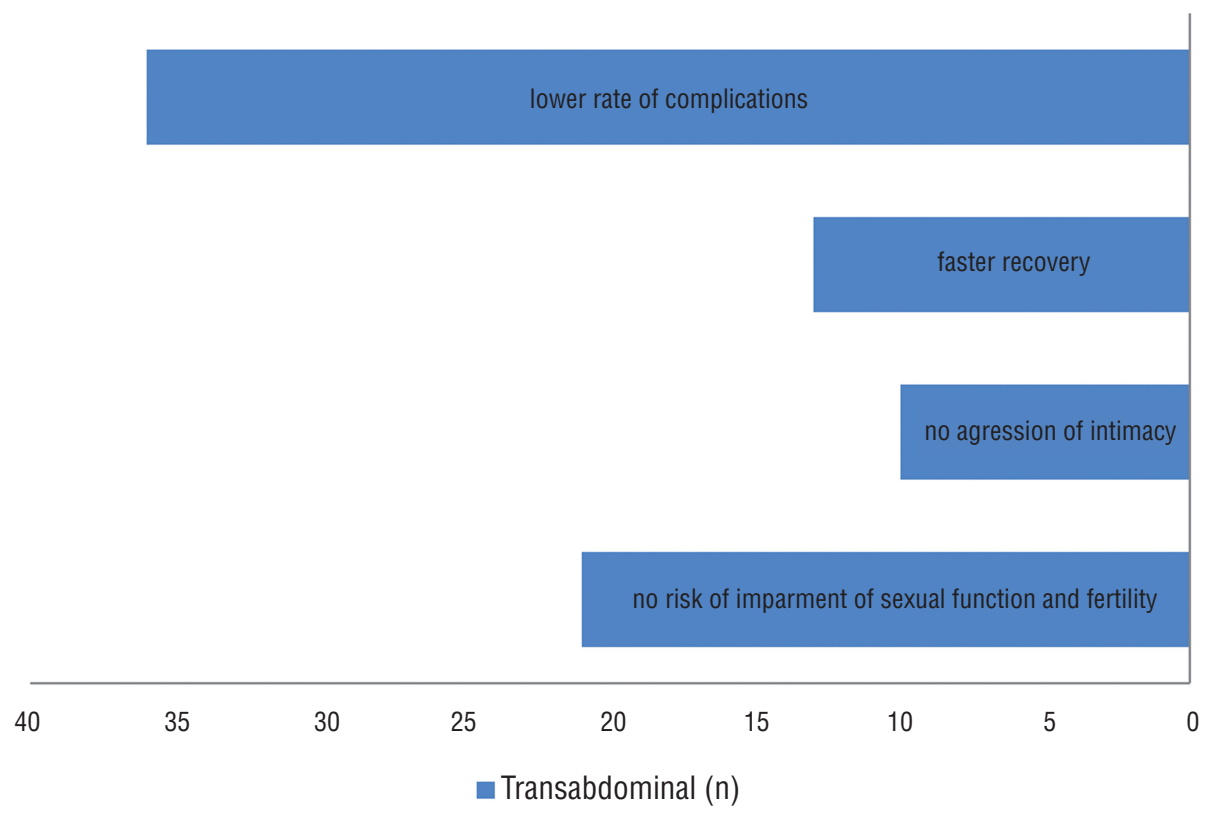


The defenders of the conventional abdominal extraction justified their option with the expectation of lower complication rate and expressed concerns about sexual function and fertility. These concerns are probably restraints to widespread acceptance of transvaginal surgery. Although, studies have shown that per-operative complications are negligible when the transvaginal access is created under direct vision (12) and infection is a rare event $(\leq 1 \%)(12,13)$. Sexual function seems not to be affected by the transvaginal access while fertility questions are more controversial. (14-17).

Tanaka M, et al. assessed the long-term complications, including infertility, after transvaginal peritoneal surgery in a group of young patients. They found no evidence that this approach caused infertility or dyspareunia (18).

Female surgeons preferred the transvaginal approach, which is in agreement with similar studies conducted on NOTES, (19-21) that showed that the majority of the inquired women would opt for the transluminal procedures, not only because of the better cosmesis but also expecting a lower post operative pain and lower risk of hernia formation. Probably women see naturally the vagina as a possible route of organ delivery.

Although surgeons with practice in laparoscopy tended to be more prone to choose the vaginal route, it was the experience in vaginal surgery that clearly prompted surgeons to opt for this approach. This suggests that surgeons experienced in vaginal surgery find the vaginal extraction safe and advantageous, and on the other hand, is natural that surgeons with no experience in vaginal surgery tend to "fear" this approach.

Our results also show contrasts with similar studies conducted on NOTES. In the article published by Thele, (22) whereas $69.2 \%$ of the inquired surgeons classified transvaginal NOTES as acceptable, only $32.7 \%$ considered the procedure appropriate for abdominal surgery and just $28.8 \%$ would recommend it. Concerns with infection, visceral lesions and infertility were the most expressed arguments. Volckmann and collaborators surveyed the members of three major surgical societies; 23\% respondents demonstrated a great interest on NOTES, however, only $26 \%$ would personally undergo a NOTES procedure. Safety was considered the most important factor in the option. Probably, NOTES and NOSE, do not elicit the same concerns in the surgical community.

Public perception of new surgical procedures may not always consider all their potential risks and benefits; however it is well known the importance of public demanding in the evolution of surgical techniques. Population based surveys found a great acceptance of female public for the transvaginal procedures once safety is assured. In the study of Peterson et al. 73\% of the respondents would consider a transvaginal procedure and $68 \%$ would opt for the procedure if safety was equivalent to laparoscopy (20). Olakengil et al. surveyed female living donors about transvaginal NOTES nephrectomy; 51\% would have opted for this approach if safety was the same (23).

The present study is the first evaluating surgeons opinion on NOSE, however, it is has some limitations, namely, the use of a non validated questionnaire and the national character of the survey.

\section{CONCLUSIONS}

The transvaginal kidney retrieval was the approach of choice of the majority of the inquired gynecologists and general surgeons but not to the urologists.

The lack of experience in vaginal surgery and the apprehension of long-term effects on sexual function and fertility can be obstacles to the widespread of this technique.

\section{ACKNOWLEDGMENTS}

The authors thank the Portuguese Association of Urology, the Portuguese Association of Gynecology and the Portuguese Association of General Surgery for their collaboration in data collection process.

\section{CONFLICT OF INTEREST}

None declared. 


\section{REFERENCES}

1. Rattner D, Kalloo A; ASGE/SAGES Working Group. ASGE/ SAGES Working Group on Natural Orifice Translumenal Endoscopic Surgery. October 2005. Surg Endosc. 2006; 20:329-33.

2. Palanivelu C, Rangarajan M, Jategaonkar PA, Anand NV. An innovative technique for colorectal specimen retrieval: a new era of "natural orifice specimen extraction" (N.O.S.E). Dis Colon Rectum. 2008; 51:1120-4.

3. Nieboer TE, Johnson N, Lethaby A, Tavender E, Curr E, Garry R, et al. Surgical approach to hysterectomy for benign gynaecological disease. Cochrane Database Syst Rev. 2009;3:CD003677.

4. Torres RA, Orban RD, Tocaimaza L, Vallejos Pereira G, Arévalo JR. Transvaginal specimen extraction after laparoscopic colectomy. World J Surg. 2012; 36:1699-702.

5. Dauleh MI, Townell NH. Laparoscopic nephroureterectomy for malignancy: vaginal route for retrieval of intact specimen. Br J Urol. 1993; 72:667-8.

6. Alcaraz A, Musquera M, Peri L, Izquierdo L, García-Cruz $\mathrm{E}$, Huguet $\mathrm{J}$, et al. Feasibility of transvaginal natural orifice transluminal endoscopic surgery-assisted living donor nephrectomy: is kidney vaginal delivery the approach of the future? Eur Urol. 2011; 59:1019-25.

7. Milad MP, Milad EA. Laparoscopic morcellator-related complications. J Minim Invasive Gynecol. 2014; 21:486-91.

8. Breda G, Silvestre P, Giunta A, Xausa D, Tamai A, Gherardi L. Laparoscopic nephrectomy with vaginal delivery of the intact kidney. Eur Urol. 1993; 24:116-7.

9. Gill IS, Cherullo EE, Meraney AM, Borsuk F, Murphy DP, Falcone T. Vaginal extraction of the intact specimen following laparoscopic radical nephrectomy. J Urol. 2002; 167:238-41.

10. Box GN, Bessler M, Clayman RV. Transvaginal access: current experience and potential implications for urologic applications. J Endourol. 2009; 23:753-7.

11. Autorino R, White WM, Gettman MT, Khalifeh A, De Sio M, Lima E, et al. Public perception of "scarless" surgery: a critical analysis of the literature. Urology. 2012; 80:495-502.

12. Edwards JR, Peterson KD, Andrus ML, Dudeck MA, Pollock DA, Horan TC; et al. Healthcare Safety Network Facilities. National Healthcare Safety Network (NHSN) Report, data summary for 2006 through 2007, issued November 2008. Am J Infect Control. 2008; 36:609-26. Erratum in: Am J Infect Control. 2009; 37:425.

13. Lehmann KS, Ritz JP, Wibmer A, Gellert K, Zornig C, Burghardt J,. The German registry for natural orifice translumenal endoscopic surgery: report of the first 551 patients. Ann Surg. 2010; 252:263-70.
14. Linke GR, Luz S, Janczak J, Zerz A, Schmied BM, Siercks I, ey al. Evaluation of sexual function in sexually active women 1 year after transvaginal NOTES: a prospective cohort study of 106 patients. Langenbecks Arch Surg. 2013; 398:139-45.

15. Solomon D, Lentz R, Duffy AJ, Bell RL, Roberts KE. Female sexual function after pure transvaginal appendectomy: a cohort study. J Gastrointest Surg. 2012; 16:183-6.

16. Roussis NP, Waltrous L, Kerr A, Robertazzi R, Cabbad MF. Sexual response in the patient after hysterectomy: total abdominal versus supracervical versus vaginal procedure. Am J Obstet Gynecol. 2004; 190:1427-8.

17. Long CY, Fang JH, Chen WC, Su JH, Hsu SC. Comparison of total laparoscopic hysterectomy and laparoscopically assisted vaginal hysterectomy. Gynecol Obstet Invest. 2002; 53:214-9.

18. Tanaka M, Sagawa T, Yamazaki R, Myojo S, Dohi S, Inoue M. Evaluation of transvaginal peritoneal surgery in young female patients. Surg Endosc. 2013; 27:2619-24.

19. Li W, Xu H, Wang ZK, Fan ZN, Ba SD, Zou DW, et al. Natural Orifice Translumenal Endoscopic Surgery (NOTES): patients' perceptions and attitudes. Dig Dis Sci. 2011; 56:2415-22.

20. Peterson CY, Ramamoorthy S, Andrews B, Horgan S, Talamini M, Chock A. Women's positive perception of transvaginal NOTES surgery. Surg Endosc. 2009; 23:1770-4.

21. Lucas SM, Baber J, Sundaram CP. Determination of patient concerns in choosing surgery and preference for laparoendoscopic single-site surgery and assessment of satisfaction with postoperative cosmesis. J Endourol. 2012; 26:585-91.

22. Thele F, Zygmunt M, Glitsch A, Heidecke CD, Schreiber A. How do gynecologists feel about transvaginal NOTES surgery? Endoscopy. 2008; 40:576-80.

23. Olakkengil SA, Norwood MG, Strickland AD, Behnia-Willison F, Mohan Rao M, Hewett PJ. Perspectives of laparoscopic donors toward a new procedure: transvaginal donor nephrectomy. J Laparoendosc Adv Surg Tech A. 2010; 20:803-6. 